Vol.01/ No. 02

Pages: 93-102

https://www.irojournals.com/iroeea

DOI: https://doi.org/10.36548/jeea.2019.2.004

\title{
STORAGE SCHEDULING SCHEME FOR DISTRIBUTED ENERGY GENERATION SOURCES
}

\author{
Nayana Shetty \\ Associate Professor, Department of Electrical and Electronics Engineering, \\ NMAMIT, Nitte, Udupi, Karnataka, India \\ E-mail: nayanar401@gmail.com
}

\begin{abstract}
Innumerable methods of generating, delivering and consuming electricity has become very prominent in the recent days due to the emergence of the distributed energy resources that are comprised of renewable energy sources and the energy storage systems. The prevailing energy storage systems for the distributed energy resources has its own challenges that are related to the methods of storage, the cost of the storage and their functioning. So the paper puts forward a novel energy accumulator that is supported by a rotating magnetic core as storage for the distributed energy resources. The proposed method brings down the operational, technical and financial complexities in storage of the distributed energy resources.
\end{abstract}

Keywords: Renewable Energy sources, energy storage system, distributed energy resources, energy accumulator and rotating magnetic core.

\section{INTRODUCTION}

The usual micro-grid or the prevailing distributed energy resources (DER) is comprised of the following fundamental elements such as the (i) renewable generation that holds a solar photovoltaic or wind turbines or the both, for the major renewable resource generation, and an invertor system to connect to the renewable energy generation sources to the grid. Apart from the renewable generation sources the system also has a one or more (ii) standby generators, operated by the either the natural gas or the diesel, to deliver extra power when the energy generated by the renewable resources are insufficient and in the case of emergencies. (iii) The DER also holds the power factor correction equipment that is normally in the form of the capacitor banks to improvise the quality of the power, (iv) ultra-capacitors that provide a short-term supplementary power to smooth the transitions in the distributed sources and support load steps, and finally a (v) controls system to arrange power supply possessions and

ISSN: 2582-3051 
Journal of Electrical Engineering and Automation (EEA) (2019)

Vol.01/ No. 02

Pages: 93-102

https://www.irojournals.com/iroeea

DOI: https://doi.org/10.36548/jeea.2019.2.004

stabilize the supply with the load being serviced by the deployment. The fig .1 below shows the arrangement of the Distributed Energy Resources.

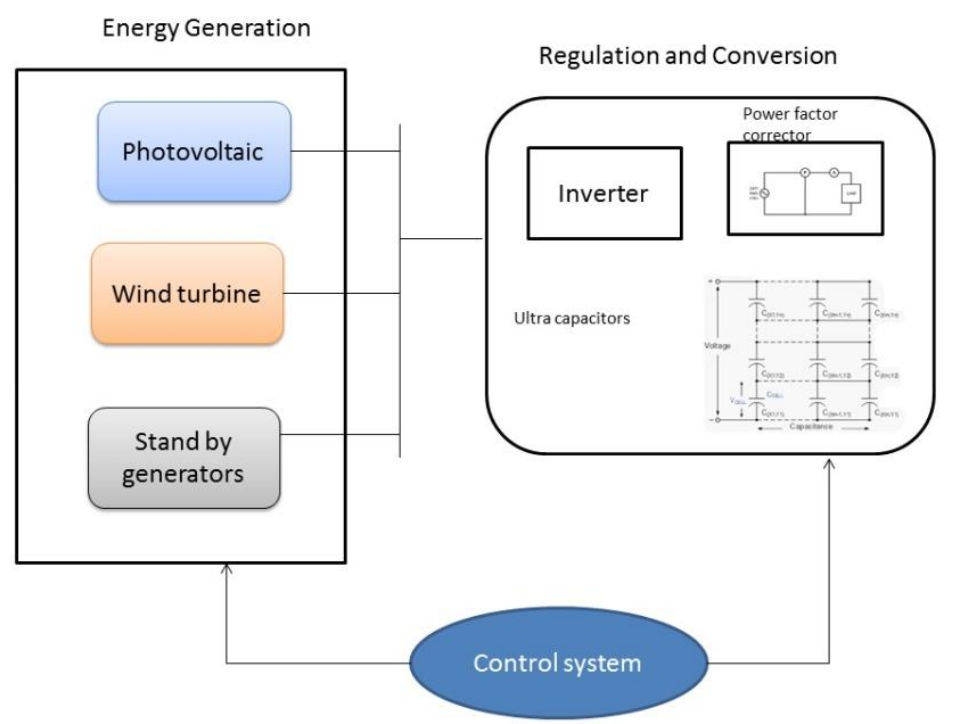

Fig.1 Distributed Energy Resources Deployment

Multitude of novel methods and applications are integrating the renewable energy sources in their task to improve the financial side of the applications. The energy accumulated minimizes the cost as well as enables to increase the revenue by the affording the grid to satisfy the requirement on the time of emergency. This is done by bringing down the utilization of the power on the regular applications such as the house holds works, charging of the car etc.

The lithium ion batteries that store a substantial amount of the renewable loads for a certain amount of period are engaged in most of the applications recently as the other batteries such as the lead acid and the flow batteries does not meet the requirement of the today's needs. The table .1 below shows the comparison of the different types of batteries available.

ISSN: 2582-3051 
Journal of Electrical Engineering and Automation (EEA) (2019)

Vol.01/ No. 02

Pages: 93-102

https://www.irojournals.com/iroeea

DOI: https://doi.org/10.36548/jeea.2019.2.004

\begin{tabular}{|c|c|c|c|c|}
\hline Parameters & Lead Acid & Flow batteries & $\mathrm{NaS}$ & Li-ion \\
\hline $\begin{array}{l}\text { Energy } \\
\text { Density }\end{array}$ & Low & $\begin{array}{l}\text { Lower than } \\
\text { Li-ion }\end{array}$ & Low & High \\
\hline Efficiency & $87 \%$ & $(55-80) \%$ & $\begin{array}{l}\text { High } \\
(92 \%)\end{array}$ & High $(100 \%)$ \\
\hline Life Cycle & $200-300$ & - & - & $500-1000$ \\
\hline Toxicity & $\begin{array}{l}\text { Highly } \\
\text { corrosive }\end{array}$ & Low & $\begin{array}{l}\text { Highly } \\
\text { corrosive }\end{array}$ & Non-Toxic \\
\hline Cost & low & High & High & $\begin{array}{l}\text { Not more than } \\
600 \$\end{array}$ \\
\hline $\begin{array}{c}\text { Others } \\
\text { essentialities }\end{array}$ & $\begin{array}{c}\text { Needs } \\
\text { continuous } \\
\text { maintenance }\end{array}$ & $\begin{array}{l}\text { High power } \\
\text { capacities for } \\
\text { load leveling } \\
\text { especially in } \\
\text { grid system }\end{array}$ & $\begin{array}{l}\text { Requires high } \\
\text { operating } \\
\text { temperature }\end{array}$ & - \\
\hline
\end{tabular}

Table.1 Comparison of Battery Parameters [7]

Initially the battery arrangement for the accumulating the renewable energy was tedious and highly challenging, as the batteries had very less lifetime, which depended on the total number of the discharges, the duration of the discharges, the rate of the recharges and the age of the batteries. So the lifespan of the battery directly depends on the number of the discharges faced by it.

For the renewable energy storage arrangement, the battery utilized faces a continuous discharge and recharge which in turn reduces the lifetime of the batteries and causes the continuous replacement of the batteries before its life expectancy. So in order to minimize the energy storage problem and the battery problem in the distributed energy resources, the paper puts forward the incorporation of the a novel energy accumulator that is supported by a rotating

ISSN: 2582-3051 
Journal of Electrical Engineering and Automation (EEA) (2019)

Vol.01/ No. 02

Pages: 93-102

https://www.irojournals.com/iroeea

DOI: https://doi.org/10.36548/jeea.2019.2.004

magnetic core as storage for the distributed energy resources to bring down the operational, technical and financial complexities in storage of the distributed energy resources.

The remaining paper is arranged with the, 2.Related works, 3.Proposed storage scheme with the reduced operational, technical and financial complexities in storage of the distributed energy resources, 4. The result evaluation and 5.Conclusion

\section{RELATED WORKS}

The sections present the prevailing storage schemes available and the measures taken to improve the prevailing storage system of the of the distributed energy sources. The author Manikandan et al [1] presents the "Controller based performance measures of speed control of electrical motor for industrial applications." The author Kumar, N. Mohan et al [2] details the "energy and power efficient system on chip with Nano sheet FET." Nirmal, D. et al [3] provides the "design and efficiency analysis of Nano carbon interconnect structures" and the author Bahn, Hyokyung et al [4] proposes the . "Efficient management of probe-based nano storage devices"

Bhalaji, N. et al [5] utilizes the soft computing in the task scheduling and the storage management in the cloud. Smys, S., and G. Ranganathan et al [6] provides the details of the manufacturing industry run by a robots Mohanty, Parimita, et al [7] presents the "PV system design for off-grid applications." and the author Zhao et al [8]proposes the "Review of energy storage system for wind power integration support" the author Yao, D. L., San Shing et al [9]puts forward the "Determination of short-term power dispatch schedule for a wind farm incorporated with dualbattery energy storage scheme."

The "Smart home energy management systems: Concept, configurations, and scheduling strategies." Was proposed by the author Zhou, Bin et al [10]. The author Yi, Jialiang et al [11] put forth the "Robust scheduling scheme for energy storage to facilitate high penetration of renewables" and the Singh, et al [12] proposes the. "Optimal power scheduling of renewable energy systems in microgrids using distributed energy storage system."

ISSN: 2582-3051 
Journal of Electrical Engineering and Automation (EEA) (2019)

Vol.01/ No. 02

Pages: 93-102

https://www.irojournals.com/iroeea

DOI: https://doi.org/10.36548/jeea.2019.2.004

Salinas, et al [13] puts forth the "Dynamic energy management for the smart grid with distributed energy resources." and the Régis, Nibaruta, et al [14] in his paper develops an Energy Flow Strategy For A Small Scale Grid-Tied Photovoltaic System Under Net-Metering." Kumar, R. Praveen, and S. Smys et al [15] details the "A novel report on architecture, protocols and applications in Internet of Things (IoT)"

\section{PROPOSED ENERGY ACCUMULATION STRATEGY}

The proposed method put forth, integrates the rotating magnetic core with the accumulator to provide a grander energy accumulation facility for the distributed energy resources for both the long as well as the short power requirements. The proposed system includes the rotating magnetic core, a DC/DC inverter system, an accumulator or a battery, a static disconnect switch, two bidirectional invertors and the lifter and the lie inductors. The fig .2 below shows the block diagram of the proposed energy accumulation system.

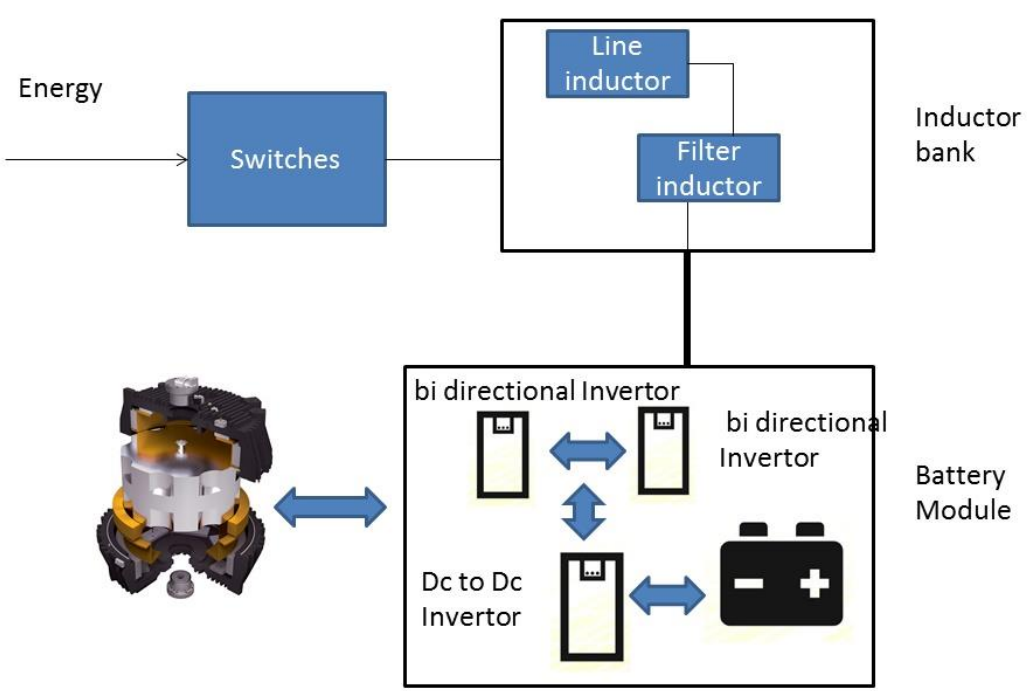

Fig.2 Proposed Block Diagram

ISSN: 2582-3051 
Journal of Electrical Engineering and Automation (EEA) (2019)

Vol.01/ No. 02

Pages: 93-102

https://www.irojournals.com/iroeea

DOI: https://doi.org/10.36548/jeea.2019.2.004

\subsection{WORKING}

The rotating magnetic core constantly spins the rotor in the low friction environment and stores the energy produced due to the movement. In cases of short power requirement due to the variations in the renewable energy production , or peak power utilization, the rotating magnetic core inertia enables the continuous spinning of the allowing the stored energy to be transformed and distributed to the grid. The battery cabinet found in the system includes a DC to DC convertor and a supplementary accumulator. The battery is usually utilized for the long term power storage and is discharged through the driver module; the rotating magnetic core is clubbed with the accumulator in the system so this seems as a single energy source. Apart from the above mentioned devices the proposed system employs two DC distribution systems to regulate and monitor the flow of the power between the DC and the Ac grid. The DC distribution system receives the DC input and converts it into AC output.

The integration of the rotating magnetic core and the energy accumulators over the potential barriers in its functioning by breaking the operational complexity and works at a much reduced cost. The proposed system expands the life span of the battery by minimizing the total number of durations.

\section{RESULTS}

The proposed rotating magnetic core integrated with the battery allows the accumulator to start discharging only for the large scale requirements thus protecting the load frequency and resulting in lower maintenance as well as the replacement cost. The fig. 3 below shows the cost reduction achieved by the proposed method.

ISSN: 2582-3051 
Journal of Electrical Engineering and Automation (EEA) (2019)

Vol.01/ No. 02

Pages: 93-102

https://www.irojournals.com/iroeea

DOI: https://doi.org/10.36548/jeea.2019.2.004

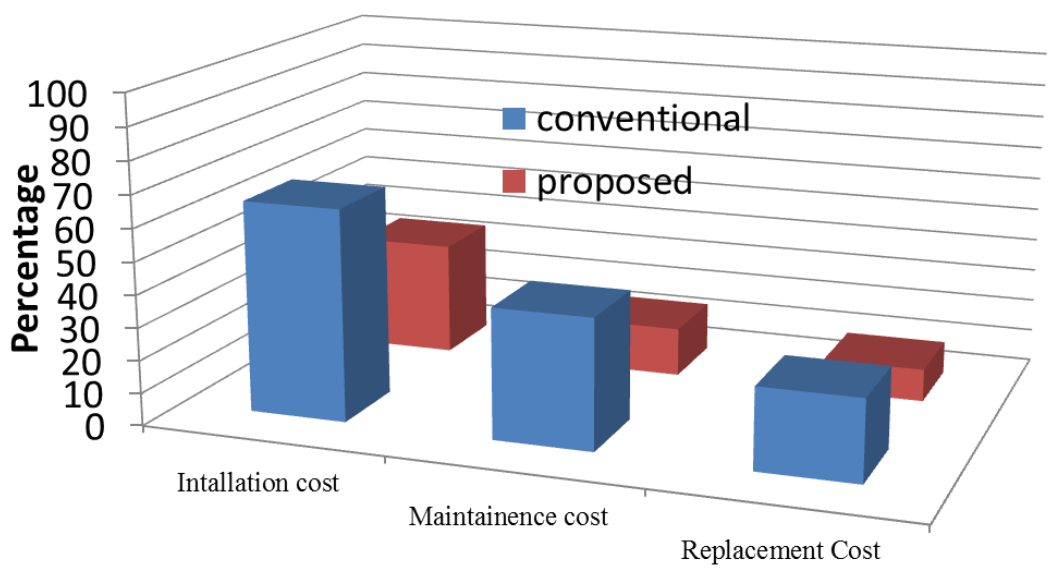

Fig.3 Cost Percentage

The fig .4 given below shows the minimization in the sharp voltage dip by installing proper sized energy accumulators, the rotating magnetic core delivers the load to the battery in the controlled manner and minimizes the initial step load discharge.

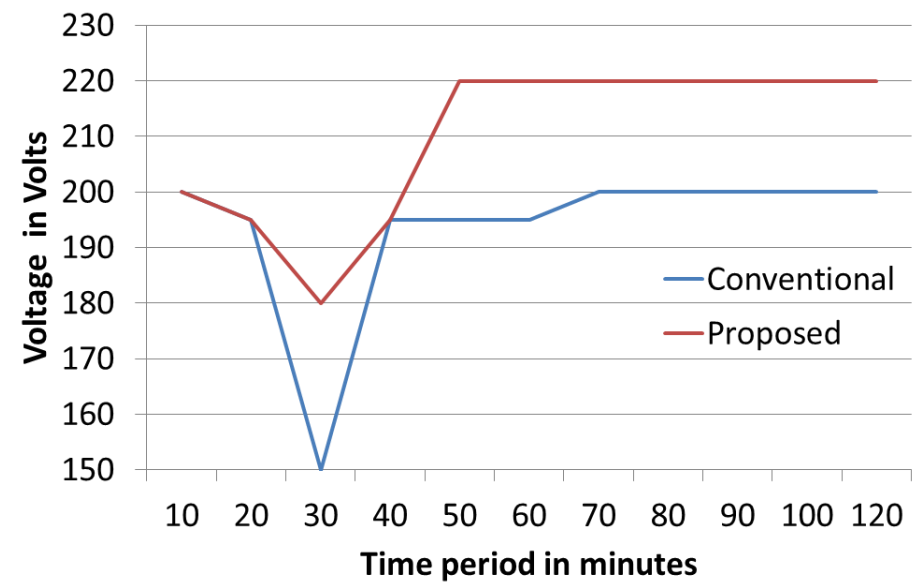

ISSN: 2582-3051 
Journal of Electrical Engineering and Automation (EEA) (2019)

Vol.01/ No. 02

Pages: 93-102

https://www.irojournals.com/iroeea

DOI: https://doi.org/10.36548/jeea.2019.2.004

Fig.4 Minimized Sharp Voltage Dip

The Table.2below provides the charging rate, number of discharges and the initial investment cost and the total maintenance and the replacement cost of the proposed accumulator and the prevailing system

\begin{tabular}{|c|c|c|}
\hline Parameters & $\begin{array}{c}\text { Proposed - Battery } \\
\text { system }\end{array}$ & Conventional Battery \\
\hline $\begin{array}{c}\text { Charging rate } \\
\%\end{array}$ & 100 & 95 \\
\hline $\begin{array}{c}\text { Number of } \\
\text { Discharges }\end{array}$ & 20 (per year ) & $(40-65)$ per year \\
\hline $\begin{array}{c}\text { Investment } \\
\text { Cost \% }\end{array}$ & 35 & 65 \\
\hline $\begin{array}{c}\text { Maintenance } \\
\text { Cost \% }\end{array}$ & 15 & 40 \\
\hline $\begin{array}{c}\text { Replacement } \\
\text { Cost \% }\end{array}$ & 10 & \\
\hline
\end{tabular}

Table.2 Comparative Analysis

\section{CONCLUSION}

The proposed novel integrated energy accumulators, remains as an optimal technology to handle the power factor challenges. This method achieves the minimized operation complexity as well as the cost by vividly altering the finance of the distributed energy resources. The system seems to be a less expensive alternative to the conventional back up generation system. The results obtained proves the capability of the proposed system in terms of cost , Charging rate, discharging rate etc.

\section{References}

ISSN: 2582-3051 
Journal of Electrical Engineering and Automation (EEA) (2019)

Vol.01/ No. 02

Pages: 93-102

https://www.irojournals.com/iroeea

DOI: https://doi.org/10.36548/jeea.2019.2.004

[1] Manikandan, R., and S. Smys. "Controller based performance measures of speed control of electrical motor for industrial applications." In 2017 International Conference on Inventive Systems and Control (ICISC), pp. 1-5. IEEE, 2017.

[2] Kumar, N. Mohan. "ENERGY AND POWER EFFICIENT SYSTEM ON CHIP WITH NANOSHEET FET." Journal of Electronics 1, no. 01 (2019): 52-59..

[3] Nirmal, D. "DESIGN AND EFFICIENCY ANALYSIS OF NANOCARBON INTERCONNECT STRUCTURES." Journal of Electronics 1, no. 01 (2019): 12-23.

[4] Bahn, Hyokyung. "EFFICIENT MANAGEMENT OF PROBE-BASED NANO STORAGE DEVICES." Journal of Electronics 1, no. 01 (2019): 1-11.

[5] Bhalaji, N. "DELAY DIMINISHED EFFICIENT TASK SCHEDULING AND ALLOCATION FOR HETEROGENEOUS CLOUD ENVIRONMENT." Journal of trends in Computer Science and Smart technology (TCSST) 1, no. 01 (2019): 51-62.

[6] Smys, S., and G. Ranganathan. "ROBOT ASSISTED SENSING, CONTROL AND MANUFACTURE IN AUTOMOBILE INDUSTRY." Journal of ISMAC 1, no. 03 (2019): 180-187.

[7] Mohanty, Parimita, K. Rahul Sharma, Mukesh Gujar, Mohan Kolhe, and Aimie Nazmin Azmi. "PV system design for off-grid applications." In Solar Photovoltaic System Applications, pp. 49-83. Springer, Cham, 2016.

[8] Zhao, Haoran, Qiuwei Wu, Shuju Hu, Honghua Xu, and Claus Nygaard Rasmussen. "Review of energy storage system for wind power integration support." Applied energy 137 (2015): 545-553.

[9] Yao, D. L., San Shing Choi, King Jet Tseng, and T. T. Lie. "Determination of short-term power dispatch schedule for a wind farm incorporated with dual-battery energy storage scheme." IEEE Transactions on Sustainable Energy 3, no. 1 (2011): 74-84.

[10] Zhou, Bin, Wentao Li, Ka Wing Chan, Yijia Cao, Yonghong Kuang, Xi Liu, and Xiong Wang. "Smart home energy management systems: Concept, configurations, and scheduling strategies." Renewable and Sustainable Energy Reviews 61 (2016): 30-40.

[11] Yi, Jialiang, Pádraig F. Lyons, Peter J. Davison, Pengfei Wang, and Philip C. Taylor. "Robust scheduling scheme for energy storage to facilitate high penetration of renewables." IEEE Transactions on Sustainable Energy 7, no. 2 (2015): 797-807.

[12] Singh, Shakti, Mukesh Singh, and Subhash Chandra Kaushik. "Optimal power scheduling of renewable energy systems in microgrids using distributed energy storage system." IET Renewable Power Generation 10, no. 9 (2016): 1328-1339.

ISSN: 2582-3051 
Journal of Electrical Engineering and Automation (EEA) (2019)

Vol.01/ No. 02

Pages: 93-102

https://www.irojournals.com/iroeea

DOI: https://doi.org/10.36548/jeea.2019.2.004

[13] Salinas, Sergio, Ming Li, Pan Li, and Yong Fu. "Dynamic energy management for the smart grid with distributed energy resources." IEEE Transactions on Smart Grid 4, no. 4 (2013): 2139-2151.

[14] Régis, Nibaruta, Christopher Maina Muriithi, and Livingstone Ngoo. "Energy Flow Strategy For A Small Scale Grid-Tied Photovoltaic System Under Net-Metering."

[15] Kumar, R. Praveen, and S. Smys. "A novel report on architecture, protocols and applications in Internet of Things (IoT)." In 2018 2nd International Conference on Inventive Systems and Control (ICISC), pp. 1156-1161. IEEE, 2018. 